\title{
Stereotaxic Thalamotomy for Intractable
} Pain

\section{E.S.}

The London Hospital, London

\section{Abstract}

The treatment of intractable pain in patients who have a normal life expectancy has presented great difficulties in view of the propensity of the nervous system to recover from therapeutic surgical lesions which may provide only temporary benefit to the individual. It is generally accepted that peripheral interruptions, e.g., neurectomy, rhizotomy and ventrolateral cordotomy, are unlikely to be permanently effective in the control of such painful states as anaesthesia dolorosa, post-herpetic neuralgia, post-cordotomy dysaesthesia, etc. Interruptions more central in the neural organization have been sought in consequence. Since 1961, 25 patients with benign causes of intractable pain have been treated stereotaxically with posterior-medial thalamotomy, and a long-term follow-up of the results beneficial and otherwise can now be given. The surgical lesions have been placed in relation to the position of the centro-medianum parafascicularis nuclear complex [Andrew and Watkins, 1969]. The placement of the lesions was originally empirical in nature, but a rational basis related to current anatomical and physiological concepts of the pathophysiology of intractable pain may now be offered. 